EPiC Series in Engineering
Volume 3, 2018, Pages 1692-1697
HIC 2018. 13th International
Conference on Hydroinformatics

\title{
Sediment flushing from reservoir and ecological impacts
}

\author{
Giuseppe Roberto Pisaturo ${ }^{1 *}$ and Maurizio Righetti ${ }^{1 \dagger}$ \\ ${ }^{1}$ University of Bozen, Bozen, Italy \\ gpisaturo@unibz.it, maurizio.righetti@unibz.it
}

\begin{abstract}
Dams cause a sediment transport trapping phenomenon and the effects can be the reduction of reservoirs operations, the decreasing of the storage, a channel erosion of the downstream watercourse and habitats pauperization. A possible method used to preserve the reservoir volume and the sediment continuity downstream the dam is to operate sediment flushing. In this work, the sediment flushing phenomena and its impact on morphology and ecology is investigated. In particular two possible flushing strategies are proposed. The two strategies differ for the flow rate, sediment concentration and event duration. The results are obtained using an original CFD model developed at the University of Trento. The CFD model has the possibility to simulate the erosion and deposition phenomena and to calculate the severity of the ill effects (SEV parameter) for juvenile and adult Salmonids. The results showed that the two strategies have very different effects on morphology and habitat. The strategy that involve lower flow rate and concentration with higher event duration, seems to minimize the deposition phenomena and the effects on the habitat.
\end{abstract}

\section{Introduction}

Dams cause a sediment transport trapping phenomenon. The effects can be the reduction of reservoirs operations and the decreasing of the storage. Moreover, there is a clear evidence of downstream channel erosion and aquatic habitats pauperization resulting from sediment trapping (Habersack et al., 2014; Kondolf et al., 2014). Typically, both suspended load and bed load are entrapped in the reservoir close to the dam and only a small fraction of suspended sediment transport is bypassed through turbines and then given back in the downstream reach. Therefore, the sediment continuity, that is a fundamental condition for maintaining a good ecological status of a watercourse, is compromised.

\footnotetext{
* Researcher at University of Bozen

$\uparrow$ Professor at University of Bozen
} 
A possible method used to preserve the reservoir volume and the sediment continuity downstream the dam is to operate sediment flushing, which consist of a controlled dam's bottom outlet gates opening (White, 1990).

However, it is necessary to predict the sediment transport behavior that is released in the receiving watercourse, in order to minimize the possible ecological impacts for benthos and fishes (Grimardias et al., 2017).

In the present study the results of a CFD model are presented, in which the deposition end erosion phenomena downstream a dam is reproduced.

Moreover, the ecological impact of the suspended sediment concentration due to the flushing is estimated. The method used to estimate the ecological impact is that proposed in (Newcombe et al., 1996) in which is suggested a possible correlation between suspended sediment concentration, duration of the event and severity (SEV parameter) of ill effects. For the present analysis, we considered the juvenile and adults Salmonids.

\section{Methods}

\subsection{Case study}

The case study concerns a generic Alpine watercourse in South Tyrol. It is used since it presents a complex morphology typical of Alpine watercourses downstream of dams. The minimum flow rate is $1.5 \mathrm{~m}^{3} / \mathrm{s}$. The presence of the dam has changed the riverbed granulometric curve.

Two possible flushing strategies are studied. The first one (Case 1) consists in a release of $2.5 \mathrm{~m}^{3} / \mathrm{s}$ with a sediment concentration (C) of $0.005 \mathrm{~m}^{3} / \mathrm{m}^{3}$ for a duration of 120 minutes. The second one (Case 2) is a release of $5.0 \mathrm{~m}^{3} / \mathrm{s}$ with a concentration (C) of $0.01 \mathrm{~m}^{3} / \mathrm{m}^{3}$ for 30 minutes. The volume of sediment that is released from the dam is consequently the same for the two hypothesized events.

\subsection{CFD model}

The fluid dynamic model, developed at the University of Trento, allows to simulate water surface motions with nonhydrostatic correction (Casulli and Zanolli, 2002). The CFD model also has the possibility to consider wetting and drying of computational cells. In the hydrodynamic solver part, Reynolds equations (RANS) are solved for the continuity and conservation of momentum, coupled with the volume conservation condition and the free surface equation. For the turbulent terms in the RANS equation, the $k-\varepsilon$ turbulence model is applied to determine the eddy viscosity. In order to determine the eddy viscosity, the single equation is split up into two independent transport equations that can be locally solved with an implicit Newton method. Finally, the CFD model has the possibility to simulate suspended sediment transport and the erosion and deposition phenomena. For these purposes, an erosion rate equation is implemented in the model and it is derived from laboratory experiments to take into account also effects of porous immobile macro-roughness (the gravel bed) on the near bed fine sediment transport processes.

In particular the numerical simulation of fine sediment transport over an immobile gravel is performed introducing some original closure relations experimentally evaluated in laboratory at University of Trento (Mohajeri et al., 2016; Tarekegn, 2015).

The mean diameter of the sediment used for the analyses is $\mathrm{d}_{50}=0.15 \mathrm{~mm}$.

For the hydraulic part, the numerical model was already tested with good results between field measurements and simulated results in the work of (Pisaturo et al., 2017) 


\section{Results and discussion}

The purpose of the present work it is not to evaluate the efficiency of the CFD model in well represent the flow view. This results were already achieved in (Pisaturo et al., 2017), where the same case study was analyzed.

In this case the purpose is to understand if different flow waves, during flushing operations, can modify the local morphology of the reach.

Moreover, the aim is to quantify, based on SEV parameter, if different management of the flushing operations can increase or decrease the fish mortality probability.

Respect the change in local morphology, Figure 1 and Figure 2, compares the results for Case 1 and Case 2.

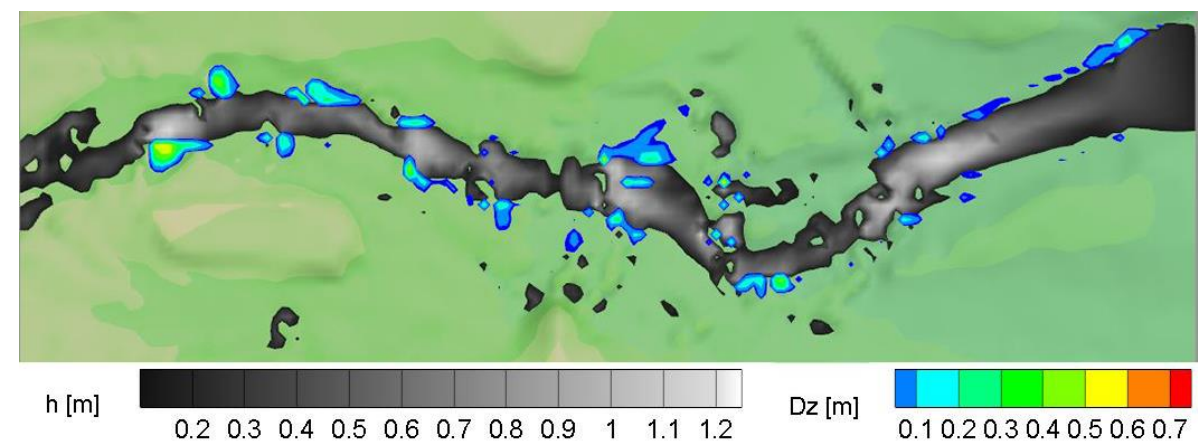

Figure 1. Water depth $(\mathrm{h}[\mathrm{m}])$ and deposition areas $(\mathrm{Dz}[\mathrm{m}])$ for Case 1.

$(\mathrm{Q}=2.5 \mathrm{~m} 3 / \mathrm{s}, \mathrm{C}=0.005 \mathrm{~m} 3 / \mathrm{m} 3$, Duration $=120 \mathrm{~min})$

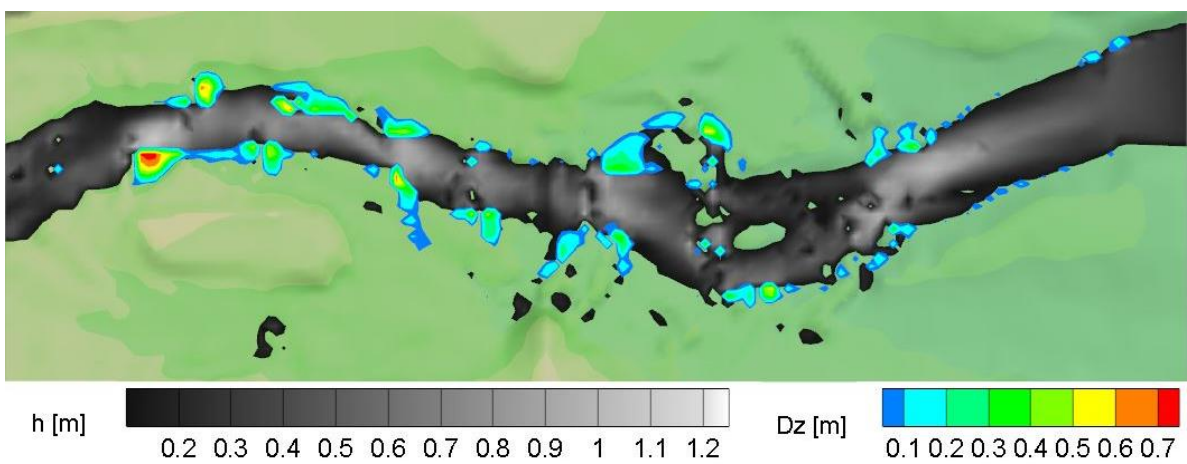

Figure 2. Water depth (h $[\mathrm{m}])$ and deposition areas $(\mathrm{Dz}[\mathrm{m}])$ for Case 2.

$(\mathrm{Q}=5.0 \mathrm{~m} 3 / \mathrm{s}, \mathrm{C}=0.01 \mathrm{~m} 3 / \mathrm{m} 3$, Duration $=30 \mathrm{~min})$

Considering a duration of the event of 120 minutes with $Q=2.5 \mathrm{~m}^{3} / \mathrm{s}$ and low sediment concentration, we can observe (Figure 1) the deposition phenomena especially in areas near the riverbanks and downstream morphological structures present in the river, such as groynes and boulders. The maximum variation of the bed elevation is around $0.5 \mathrm{~m}$.

Increasing the flow rate (Case $2: \mathrm{Q}=5.0 \mathrm{~m}^{3} / \mathrm{s}, \mathrm{C}=0.01 \mathrm{~m}^{3} / \mathrm{m}^{3}$, duration $=30$ minutes) (Figure 2), although the duration of the event is a fourth of Case 1 duration, the sediment deposition is greater 
with a maximum deposition of about $0.7 \mathrm{~m}$. The areas involved in deposition phenomena are bigger but located similarly to Case 1, near riverbanks and downstream groynes and boulders.

The sediment deposition downstream this type of structures is well explained in literature (Armanini et al., 2010) and the CFD model seems to well reproduce the phenomena.

It is to underline that the change in time of the morphology implies a change in the flow field.

Figure 3 and Figure 4 represent the SEV values for Case 1 and Case 2. To underline that, as reported in (Newcombe et al., 1996), SEV values higher than 9 are connected with lethal and paralethal effects. For this reason, the result of SEV are represented in the range from 2 to 8 .

Comparing the SEV values for Case 1 and Case 2 is interesting to note that the results are clearly different. For the Case 1 (Figure 3) the SEV parameter is always lower than 8, corresponding to a moderate habitat degradation. Moreover, is possible to note that some areas present lower SEV values, especially near the riverbanks and in secondary channels. In these areas the flow presents a lower sediment concentration, and therefore, the effects on habitat are reduced.

For Case 2 (Figure 4), the SEV values are generally higher than 8 but lower than 9. The effects on habitat can be a major physiological stress, long-term reduction in feeding rate and long-term reduction in feeding success. As for Case 1, also in Case 2 the areas of secondary channels present lower SEV values.

Comparing Case 1 and Case 2 is possible to note that the effects on habitat and bathymetry variations are lower if Case 1 strategy is adopted, meaning that is better use lower flow rates and sediment concentrations for a longer time.

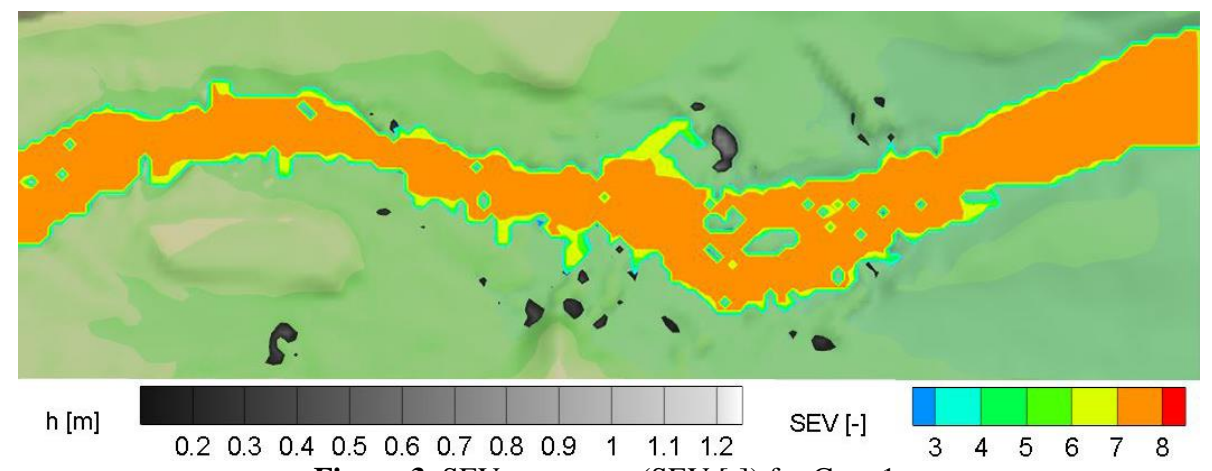

Figure 3. SEV parameter (SEV [-]) for Case 1.

$(\mathrm{Q}=2.5 \mathrm{~m} 3 / \mathrm{s}, \mathrm{C}=0.005 \mathrm{~m} 3 / \mathrm{m} 3$, Duration $=120 \mathrm{~min})$

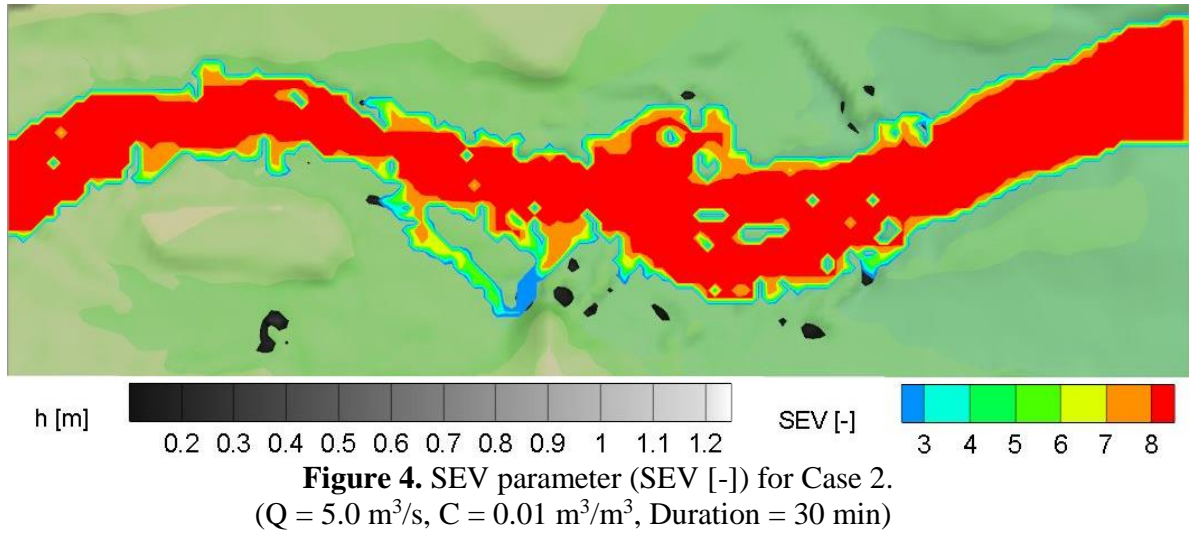




\section{Conclusions}

The present work proposed a methodology to assess the effects of sediment flushing on the downstream watercourse. Two types of flushing operations are investigated. The first one (Case 1) consists in a low flow rate, low concentration but with a long duration of the event. The second one (Case 2) presents higher flow rate and concentration but a fourth of duration. In this way, the total sediment volume from the dam is the same for the two cases.

The results showed that the impacts on morphology changes (sediment deposition) and on the ecology (severity of ill effects SEV) are lower if the first strategy is adopted.

To underline that the results are only referred to the effects on morphology and ecology, and does not take into account the possible economic effects for the dam owner that should be better investigated in a future research. The Case 1 strategy involve the use of a water volume double that in Case 2. This difference in water volume can be a missing gain for the hydropower plant.

Moreover, an interesting study should be to understand the connection of morphology changes during flushing operations with the habitat for fish and benthos. In fact, a change in morphology does not only has an effect on the flow field and on the fine sediment concentration, but cause also a different grain size distribution of the river bad. The habitat models always consider the granulometric distribution of the riverbed, due to the connection with the fish life cycle. Therefore, the coupling of habitat models with sediment transport model, should be better investigated.

\section{References}

Armanini, A., Sartori, F., Tomio, G., 2010. Analysis of a fluvial groynes system on hydraulic scale model. River FLow 2010.

Casulli, V., Zanolli, P., 2002. Semi-implicit numerical modeling of nonhydrostatic free-surface flows for environmental problems. Math. Comput. Model. 36, 1131-1149. https://doi.org/10.1016/S0895-7177(02)00264-9

Grimardias, D., Guillard, J., Cattanéo, F., 2017. Drawdown flushing of a hydroelectric reservoir on the Rhône River: Impacts on the fish community and implications for the sediment management. J. Environ. Manage. 197, 239-249. https://doi.org/10.1016/j.jenvman.2017.03.096

Habersack, H., Tritthart, M., Liedermann, M., Hauer, C., 2014. Efficiency and uncertainties in microand mesoscale habitat modelling in large rivers. Hydrobiologia 729, 33-48. https://doi.org/10.1007/s10750-012-1429-X

Kondolf, G.M., Gao, Y., Annandale, G.W., Morris, G.L., Jiang, E., Zhang, J., Cao, Y., Carling, P., Fu, K., Guo, Q., Hotchkiss, R., Peteuil, C., Sumi, T., Wang, H.-W., Wang, Z., Wei, Z., Wu, B., Wu, C., Yang, C.T., 2014. Sustainable sediment management in reservoirs and regulated rivers: Experiences from five continents. Earth's Futur. 2, 256-280. https://doi.org/10.1002/2013EF000184

Mohajeri, S.H., Righetti, M., Wharton, G., Romano, G.P., 2016. On the structure of turbulent gravel bed flow: Implications for sediment transport. Adv. Water Resour. 92, 90-104.

Newcombe, C.P., Jorgen, \&, Jensen, O.T., Jensen, J.O.T., 1996. Channel Suspended Sediment and Fisheries: A Synthesis for Quantitative Assessment of Risk and Impact JOURNAL-FISHERIES MANAGEMENT Channel Suspended Sediment and Fisheries: A Synthesis for Quantitative Assessment of Risk and Impact. North Am. J. Fish. Manag. 2, 8675693-727. https://doi.org/10.1577/1548-8675(1996)016<0693:CSSAFA>2.3.CO;2

Pisaturo, G.R., Righetti, M., Dumbser, M., Noack, M., Schneider, M., Cavedon, V., 2017. The role of 3D-hydraulics in habitat modelling of hydropeaking events. Sci. Total Environ. 575. https://doi.org/10.1016/j.scitotenv.2016.10.046 
Tarekegn, T.H., 2015. Downstream suspended sediment dynamics of reservoir sediment flushing. White, W.R., 1990. Reservoir sedimentation and flushing. Hydrol. Mt. Reg. 